\title{
Martensitic Transformation under Stress in Ferrous Alloys. Mechanical Behaviour and Resulting Morphologies
}

\author{
E. Gautier, J.S. Zhang and X.M. Zhang*
}

Laboratoire de Science et Génie des Matériaux Métalliques, URA 159 du CNRS, Ecole des Mines, Parc de Saurupt, 54042 Nancy, France

* Laboratory of Atomic Imaging of Solids, Institute of Metal Research, Academia Sinica, 72 Wenhua road, 110015 Shenyang, China

\begin{abstract}
Transformation plasticity deformation mechanisms are reviewed in the case of ferrous alloys. From experimental data, microstructural observations and numerical simulations the contributions of the different mechanisms are discussed and a schematic diagram of these evolution is proposed depending on the applied stresses and the test condition.
\end{abstract}

\section{INTRODUCTION}

The effect of stress on martensitic transformations was observed very early by Scheil for ferrous alloys [1], and since a great of number of studies are dealing with the effect of stress or strain on martensitic transformation. When a stress or a deformation is applied during the phase transformation, a simultaneous change in the mechanical behaviour is observed, called transformation induced plasticity or phase transformation plasticity.

The effects of stress and strain on martensitic transformation kinetics, mechanical behaviour and changes in martensite morphologies have been reviewed by different authors [2-4]. However, for the mechanical behaviour, the different mechanisms responsible for the transformation plasticity of the ferrous alloys were poorly discussed.

A good knowledge of these mechanisms is necessary for the modelling of the mechanical behaviour of a material during the phase transformation. Constitutive laws considering the phase transformations are necessary to describe the behaviour of TRIP steels $[5,6]$, or for calculations of internal stresses during quenching [7]. For most established models transformation plasticity deformation is considered as an additionnal inelastic deformation function of the stress, the martensite progress and in some cases the mechanical properties of the austenite. A relation between these parameters is used based on experimental data. Some recent studies are developed to improve the models using self-consistent models [6], or simulations with finite element models [8-10].

To model the material behaviour, to tests these models, the origins of transformation plasticity deformation have to be well established. The purpose of this paper, is to recall the origins of transformation plasticity, to analyse their different contributions in regard to the stress variations and the progress of the transformation. Two experimental tests are considered, transformations occurring during cooling under constant applied stress or transformation occurring during deformation. The analysis is based on transformation plasticity measurements during essentially tensile tests and microstructure observations. Results obtained by numerical simulations will be shown too.

\section{2 - TRANSFORMATION PLASTICITY MECHANISMS}

Transformation plasticity deformation occurs when a specimen transforms under stress, for stresses even lower than the yield stress of each constituant of the material. The phenomenon is observed for different transformations, transformations controlled by diffusion, or transformations involving only shear.

For martensitic transformation, it is generally attributed to two basic mechanisms : 
1 - Orientation of the martensite plates by the applied stress [11]. This effect is due to the shear component of the phase transformation deformation. It is widely illustrated by superelasticity or shape memory effect of $\mathrm{Cu}-\mathrm{Zn}-\mathrm{Al}$ alloys or other alloys [3]. The deformation associated with the transformation of a single crystal is not dependent on the level of the applied stress during transformation. It only depends on the relative orientation of the single crystal in regard to the applied stress. The deformation should be the same if the specimen (single crystal) transforms during a tensile test at constant temperature, or during cooling in the transformation range under a constant applied stress [12]. The deformation may be reversible when martensite transforms in austenite in a reversible way.

The contribution of this mechanism is then dependent on the orientation distribution of the martensite plates. For the polycrystal, two points have to be considered : i) The polycrystal presents a grain orientation distribution. The most favourable orientation of the martensite plates in regard of the applied stress will be different in each grain, and so the deformation in the direction of the applied stress as modelled by Magee [11]. ii) When plates are formed, deformation incompatibilities (near grain boundaries for example) will lead to internal stresses. These internal stresses will locally modify the stress tensor. The plate orientation will no longer be determined by the external applied stress but by the local stress state existing in the material [13]. The effect of the external applied stress will then depend on its "contribution" in the local stress tensor.

Moreover, for this mechanism one generally considers that the shear component is not modified when the transformation occurs under stress. However, theoritical and experimental works of Kosenko et al [14] and Pankova and Roytburd [15] have shown that for stress - induced martensite in ferrous alloys, the distribution of internal twins is modified and in consequence the value of the macroscopic shear deformation is modified too. The modification of the internal structure of the plate (modification of domains distribution) due to a different stress state in the presence of an applied stress, is an additionnal source of transformation plasticity deformation [16].

2- Orientation of the plastic yielding around the transforming particles when transformation deformations are accommodated by plastic deformation. This mechanism is the only one considered in the case of diffusional transformation whithout any shear component. Its contribution is then dependent on the transformation volumic variation, the applied stress, the mechanical properties of the phases and the transformation progress [17-20]. Different models were proposed to describe the transformation plasticity variations versus the transformation progress, the applied stress and the mechanical properties of the phases $[19,21]$ and numerical simulations were performed to calculate the behaviour of the material [22].

For martensitic transformation of ferrous alloys, it is necessary to consider the accommodation process of both the volumic variations and the macroscopic shear deformation. The volumic variations can be accommodated by elastic or plastic deformation. For the macroscopic shear deformation different process have to be considered. The shear deformation can be accommodated by elastic deformation in the parent phase, by formation of self accommodating plates, by elasto plastic accommodation mainly in the parent phase or by an inelastic deformation at the plate tips in the product phase [23]. The effect of an external stress can then to modify the process of the shear strain accommodation.

The following results will show the contribution of these transformation plasticity origins.

\section{3 - STUDY OF TRANSFORMATION PLASTICITY DURING COOLING UNDER STRESS}

\subsection{Experimental results}

Very few results are reported on the variations of transformation plasticity deformation versus the content of phase formed $[24,25]$. In figure 1 are reported transformation plasticity deformation variations measured versus the content of martensite during cooling under different constant applied stresses for two different Fe-Ni-C alloys. These results are similar to the one obtained previously on same alloys [25]. Transformation plasticity deformation $\varepsilon_{\mathrm{pt}}$ is defined as : $\varepsilon_{\mathrm{pt}}(\mathrm{x})=\varepsilon_{\sigma}(x)-\varepsilon_{0}(x)$ where $\varepsilon_{\sigma}(x)$ and $\varepsilon_{0}(x)$ are the deformations due to the formation of a content of martensite $X$, under a stress equal to $\sigma$ and to 0 respectively .

For the two alloys, transformation plasticity deformation increases non linearly with the transformation progress. The slope of the curve $\varepsilon_{\mathrm{pt}}=\mathrm{f}(\mathrm{X})$ is maximal at the beginning of the transformation and lowers when $\mathrm{X}$ increases whatever the applied stress. For the Fe-25Ni-0.66C alloy with the lower Ms temperature, 
fig $1 \mathrm{~b}$, the value of $\varepsilon_{\mathrm{pt}}$ is much lower than for the $\mathrm{Fe}-20 \mathrm{Ni}-0.5 \mathrm{C}$ alloy under the same stress and for the same martensite content. Figure 2 shows the variations of $\varepsilon_{\mathrm{pt}}$ normalised to martensite content $\left(\Delta \varepsilon_{\mathrm{p}} / \Delta \mathrm{X}\right.$ ) versus $\sigma$ for three given martensite contents. For the Fe-20Ni-0.5C alloy, three ranges can be defined where $\Delta \varepsilon_{\mathrm{p}} / \Delta \mathrm{X}$ increases slowly with $\sigma$ up to $50 \mathrm{MPa}$,then increases rapidly until $200 \mathrm{MPa}$. For stresses higher than $200 \mathrm{MPa}, \Delta \varepsilon_{\mathrm{p}} / \Delta \mathrm{X}$ increases again slowly. These variations are similar for all given values of martensite content. However, for a same value of $\sigma, \Delta \varepsilon_{\mathrm{pt}} / \Delta \mathrm{X}$ decreases with the increase of $\mathrm{X}$, as mentioned above. For the Fe-25Ni-0.66C alloy, we observe similar variations but the applied stress domains limits are different compared to the previous alloy low increase in the range $0-280 \mathrm{MPa}$, rapid increase in the range $280-400 \mathrm{MPa}$.
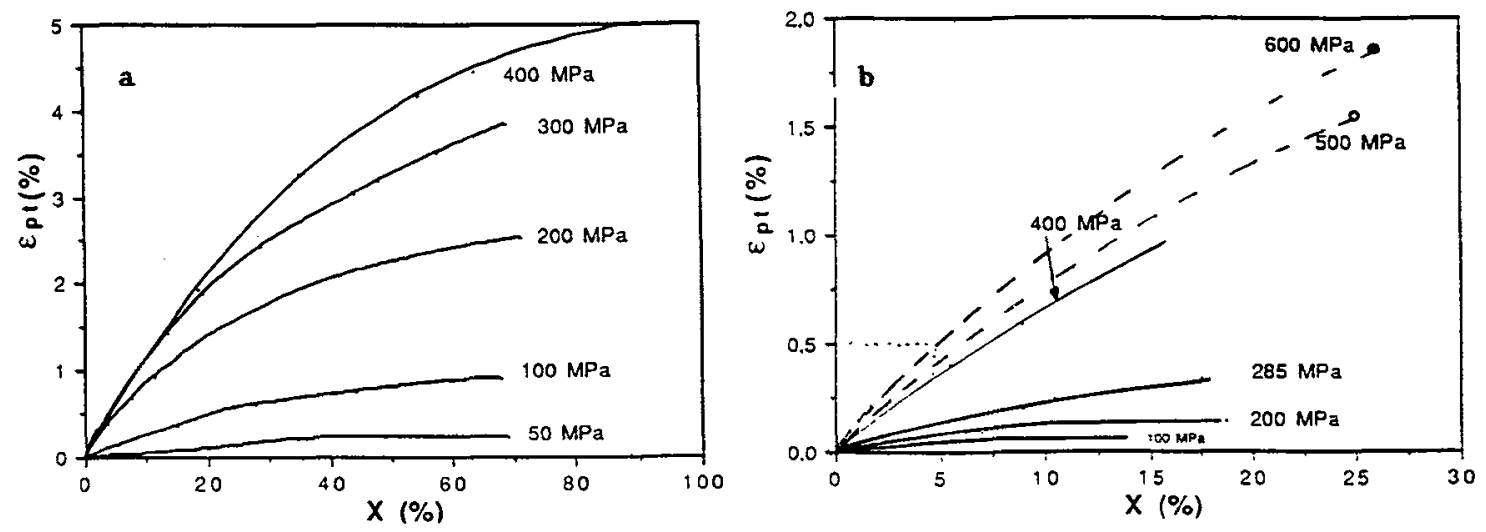

Figure 1 : Variatons of transformation plasticity deformation versus the content of martensite obtained during cooling under different applied stresses. a) $\mathrm{Fe}-20 \mathrm{Ni}-0.5 \mathrm{C}$ alloy $\mathrm{Ms}=-35^{\circ} \mathrm{C}$; b) $\mathrm{Fe}-25 \mathrm{Ni}-0.66 \mathrm{C}$ alloy $\mathrm{Ms}=-153^{\circ} \mathrm{C}$

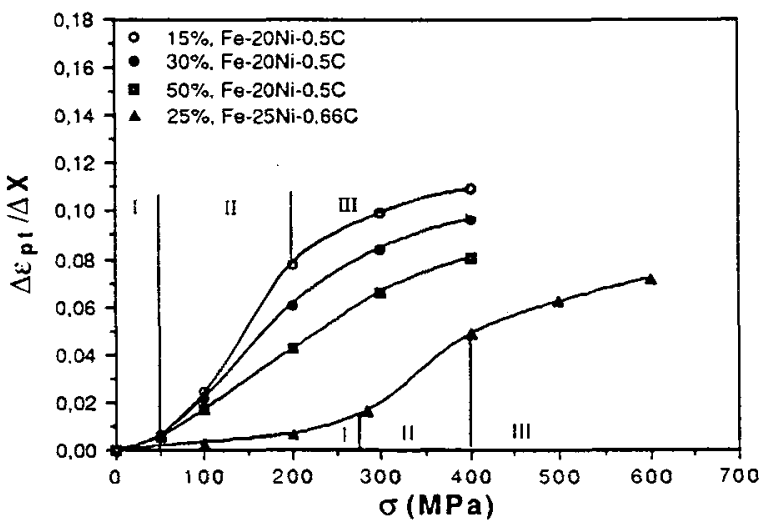

Figure 2 : Variations of transformation plasticity deformations normalized to the amount of phase formed versus the applied stress for different content of martensite.

The deformations associated with the reverse transformation $\alpha^{\prime} \rightarrow \gamma$, have been measured during a rapid heating. No stress was applied during the heating [26]. The reversible deformation associated with the transformation plasticity is defined as $\varepsilon_{\mathrm{rep}}=\varepsilon_{\mathrm{r}} \varepsilon_{\mathrm{r} 0}$, where $\varepsilon_{\mathrm{r}}$ represents the reversible deformation measured for a specimen for which a content of martensite $X$ was transformed under stress $\sigma$, and the value $\varepsilon_{r} 0$, corresponds to the reverse deformation for the same amount of martensite $\mathrm{X}$ formed without applied stress.

We present in figure 3 the variations of $\varepsilon_{\mathrm{rep}}$ normalized to $\mathrm{X}\left(\Delta \varepsilon_{\mathrm{rep}} / \Delta \mathrm{X}\right)$ versus $\sigma$, as the variations of $\Delta \varepsilon_{\mathrm{p}} / \Delta \mathrm{X}$. We have considered tests for which $\mathrm{X}$ lies in the range of 14-15\% for the Fe-20Ni-0.5C alloy and of $10-18 \%$ for the Fe-25Ni-0.66C alloy. For the Fe-20Ni-0.5C alloy, $\Delta \varepsilon_{\text {rep }} / \Delta \mathrm{X}$ increases very slowly with $\sigma$. From about $200 \mathrm{MPa}, \Delta \varepsilon_{\mathrm{rep}} / \Delta \mathrm{X}$ remains approximately constant irrespective of $\sigma$. By contrast, for the Fe-25Ni-0.66C alloy, $\Delta \varepsilon_{\mathrm{rep}} / \Delta \mathrm{X}$ increases with $\sigma$ until $400 \mathrm{MPa}$. The comparison between $\Delta \varepsilon_{\mathrm{rep}} / \Delta \mathrm{X}$ and $\Delta \varepsilon_{\mathrm{p} v} / \Delta \mathrm{X}$ shows that in the first stress range I, i.e. for a stress up to $50 \mathrm{MPa}$ for the Fe-20Ni-0.5C alloy and for a stress up to $200-280 \mathrm{MPa}$ for the $\mathrm{Fe}-25 \mathrm{Ni}-0.66 \mathrm{C}$ alloy, the reversible deformation is nearly equivalent to the transformation plasticity deformation. In the second stress range II, a difference between these two terms is observed which increases as stress increases. 

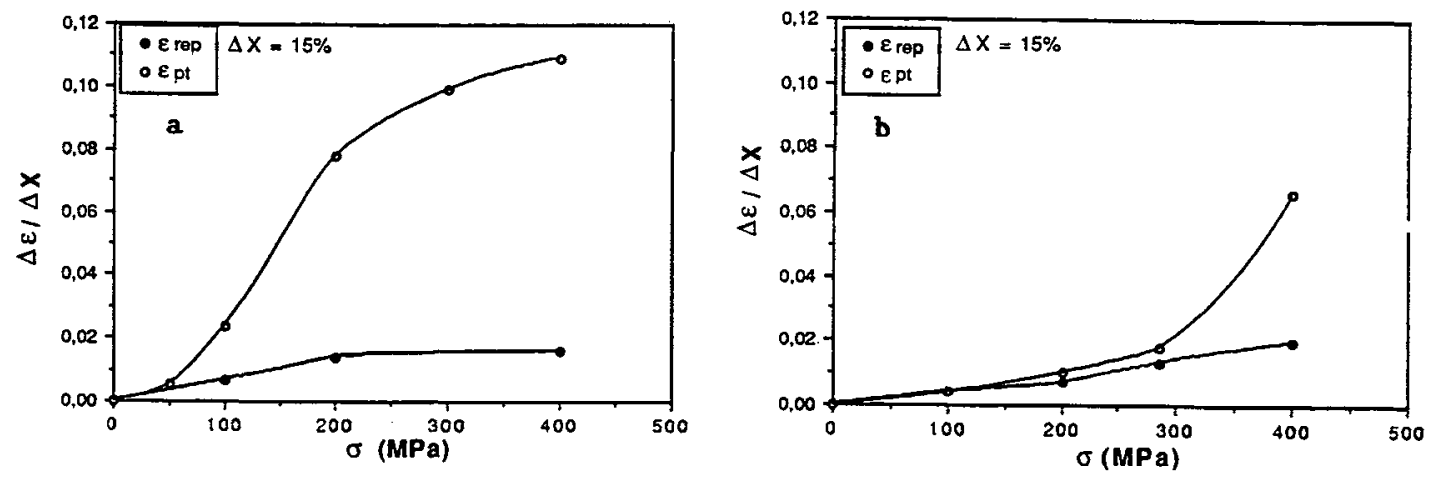

Figure 3 : Variations of reversible transformation plasticity deformations and transformation plasticity deformations normalized to the amount of martensite formed versus the applied stress during cooling. a) $\mathrm{Fe}-20 \mathrm{Ni}-0.5 \mathrm{C}$ alloy $\mathrm{Ms}=-35^{\circ} \mathrm{C}$; b) $\mathrm{Fe}-25 \mathrm{Ni}-0.66 \mathrm{C}$ alloy $\mathrm{Ms}=-153^{\circ} \mathrm{C}$

\subsection{Discussion and numerical simulations}

The results point out that the reversible deformation is larger than the volumic variation, it increases as the applied stress increases, and when the martensite content increases [26]. It is significant of an orientation of the martensite plates. This orientation effect decreases with the increase of $X$.

The comparison of the reversible deformation to the transformation plasticity deformation shows that for $15 \%$ martensite, the small amount of transformation plasticity deformation is reversible if the applied stress during transformation does not exceed $50 \mathrm{MPa}$ for the Fe-20Ni-0.5C alloy and 250MPa for the Fe-25Ni$0.66 \mathrm{C}$ alloy. This is clearly indicating that in the first stress range $\mathrm{I}$, the transformation plasticity deformation is due to the first mechanism, orientation of the plates or the domains, and the deformation is reversible as the reverse transformation proceeds.

Morever, the results for the two alloys show that the rapid increase of transformation plasticity in stress range II is linked to a non reversible mechanical behaviour of the alloys. The microstructures observed for specimens transformed under different stresses (figs. 4 and 5) reveal that a favourable orientation of the plates is observed in the grain when the stress is increased. The orientation is clearly observed when the stress reaches a value of $150 \mathrm{MPa}$ for the $\mathrm{Fe}-20 \mathrm{Ni}-0.5 \mathrm{C}$ alloy and a value of $400 \mathrm{MPa}$ for the Fe-25Ni$0.66 \mathrm{C}$ alloy. It is interesing to note that these values are near the yield strength of the austenite [26]. Moreover, the morphology of the plate is modified. For the Fe-25Ni-0.66C alloy the plates thicken when the large increase in transformation plasticity is observed. For the Fe-20Ni-0.5C alloy the plates width lowers.

From the microstructural observations it is clear that the contribution of the "plate orientation" increases as the stress increases, but it does not result in an increase in the reversible deformation. The occurence of a clear orientation of the martensite plates when stress is increased is significant of a large influence of the applied stress to the orientation of the plate. This is reached if the internal stresses due to deformation incompatibilities are relaxed. As this orientation effect becomes more sensitive when the applied stress reaches a value near the yield stress of the austenite, one can conclude that the relaxation of the internal stresses occurs by plastic deformation of the austenite. Also as the shear component is relaxed by plastic deformation of the austenite, less self accommodating plates will be formed and an increasing contribution of the first mechanism is observed. 1 When stress increases ans its value is near the yield stress of the austenite, the two mechanisms are acting, and the second mechanism favors the first one.

\footnotetext{
${ }^{1}$ The change in the relaxation process can also explain the increase in width for the $\mathrm{Fe}-25 \mathrm{Ni}-0.66 \mathrm{C}$ alloy [27].
} 

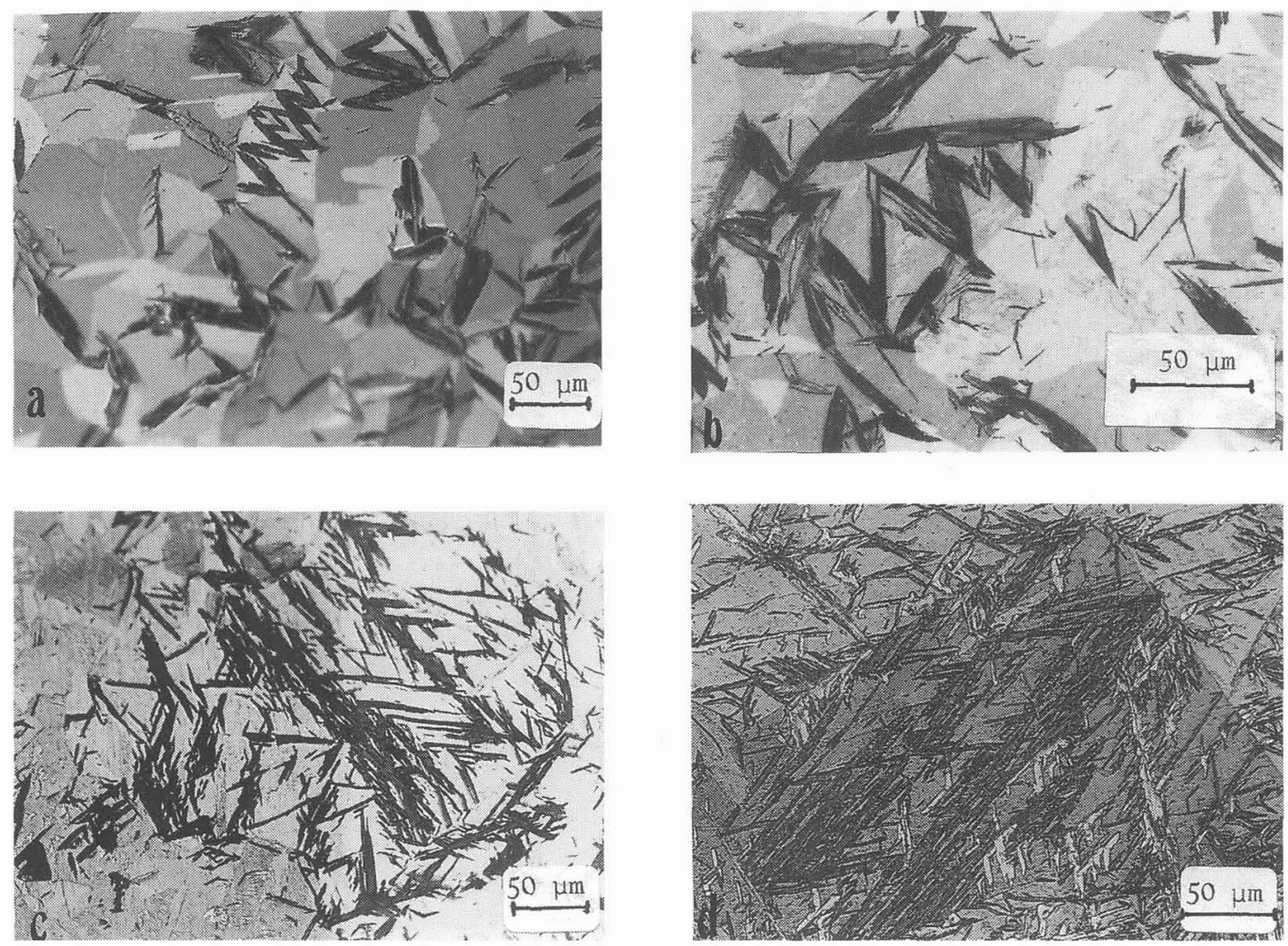

Figure 4 : Optical micrographs of specimen transformed during cooling under various constant applied stresses for the Fe$20 \mathrm{Ni}-0.5 \mathrm{C}$ alloy. a) $\sigma=0 \mathrm{MPa}$ ) $\sigma=50 \mathrm{MPa}$, c) $\sigma=200 \mathrm{MPa}$, d) $\sigma=300 \mathrm{MPa}$

For stresses larger than 250MPa for the Fe-20Ni-0.5C alloy (range III), the decrease in transformation plasticity as stress increases is related to the saturation effect of the plate orientation. Most of the plates present the favorable orientation, and the increase in transformation plasticity deformation is related to the second mechanism.

These different mechanisms and their contribution versus the applied stress for a low martensite content are schematically drawn in figure 6. As martensite content increases, the limits of the domains at which these mechanisms intervene are modified. The degree of plate orientation decreases as the martensite content increases. Experimentaly this could be observed considering transformation plasticity variations versus the martensite content for an applied stress of $50 \mathrm{MPa}$ and for the $\mathrm{Fe}-20 \mathrm{Ni}-0.5 \mathrm{C}$ alloy. For martensite contents larger than $25 \%$, the transformation plasticity deformation does not increase further. That means that only plate orientation occurs at that stress level, and the orientation distribution of the plates is random at $\mathrm{X}>0.25$. For larger stresses, this orientation distribution becomes random at much larger martensite content.

Micromechanical models (2D or 3D finite element models (FEM)) were developed to calculate the mechanical behaviour during the transformation, to estimate the contributions of the different mechanisms and to analyse the role of the local stress state [8-10,27,28]. Considering the hypothesis that a plate is described by a volumic variation and a constant shear strain, the evolution of transformation strain or/and the plate orientation distribution were calculated. The progress of the transformation and the plate orientation are determined using a transformation criteria [28]. 

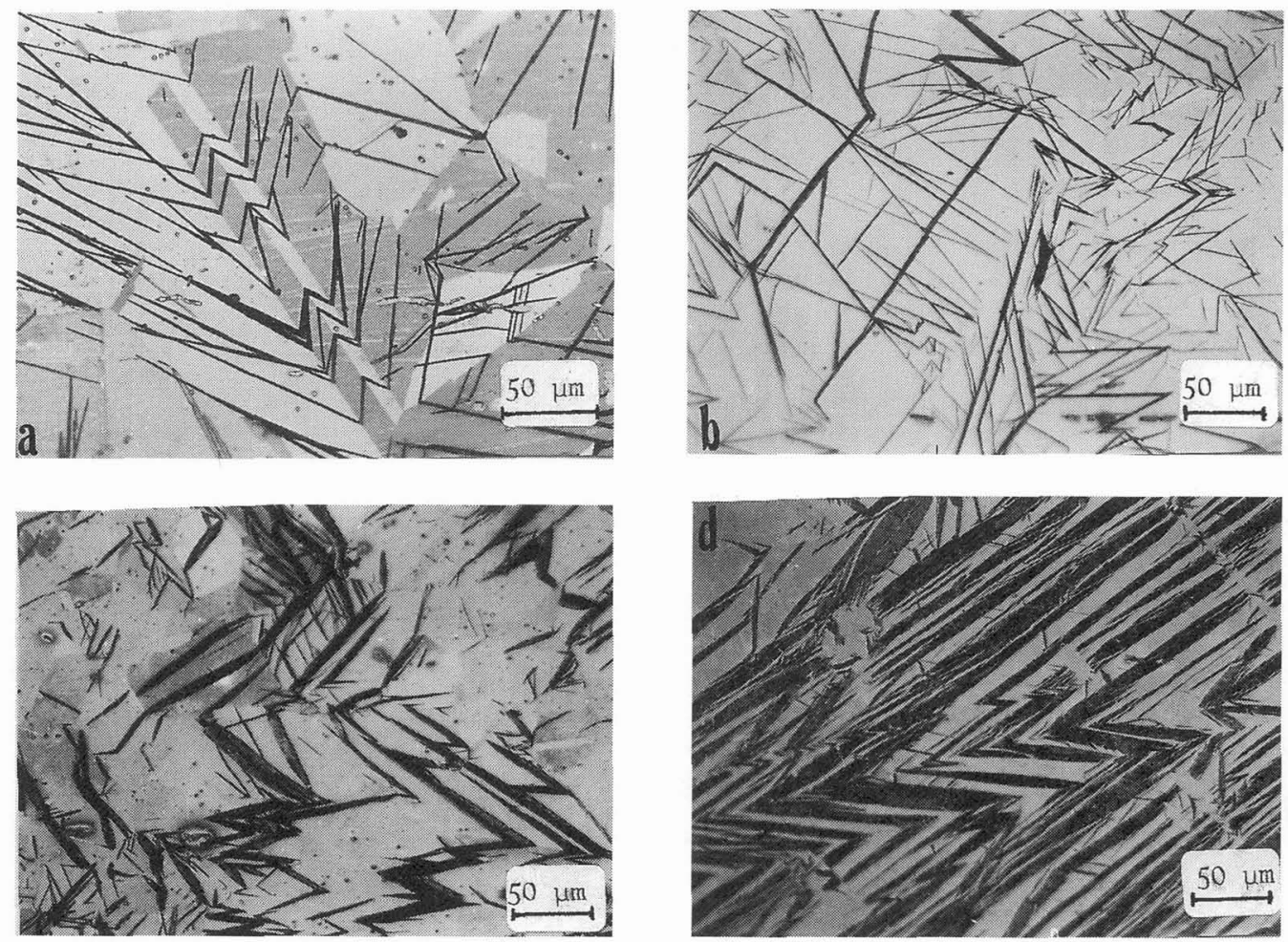

Figure 5 : Optical micrographs of specimen transformed during cooling under various constant applied stresses for the Fe$25 \mathrm{Ni}-0.66 \mathrm{C}$ alloy. a) $\sigma=0 \mathrm{MPa}$ b) $\sigma=285 \mathrm{MPa}$, c) $\sigma=500 \mathrm{MPa}$, d) $\sigma=600 \mathrm{MPa}$

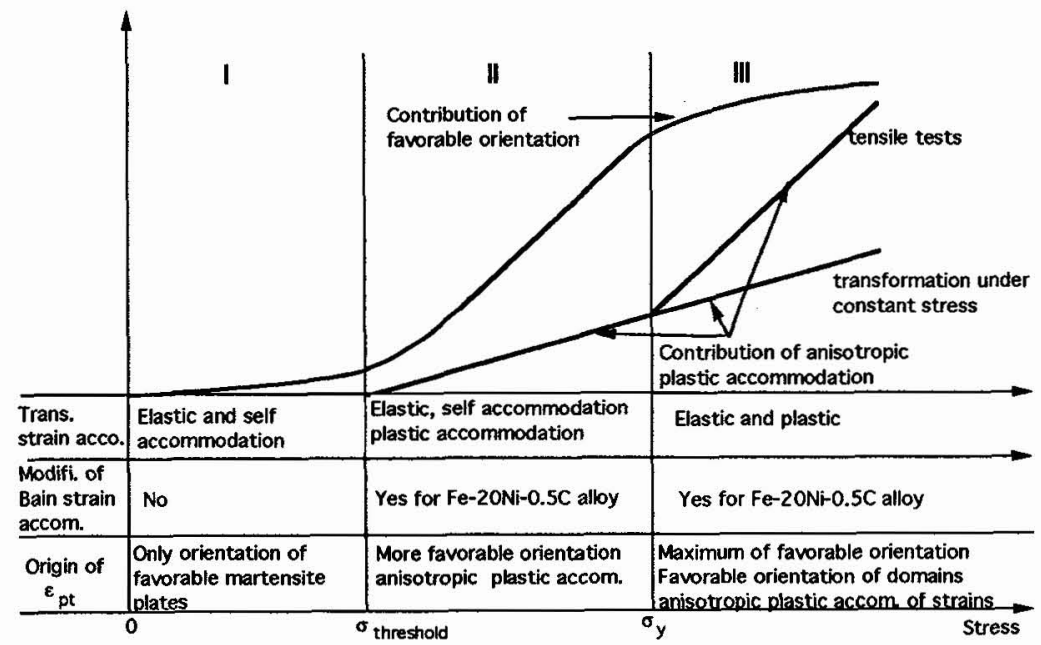

Figure 6 : Schematic contribution of the different mechanisms to the transformation plasticity deformation. 
With a simplified 2D FEM with one central transforming mesh, corresponding to one grain, surrounded by an external mesh, corresponding to the external medium with which the transforming grain interacts, and taking an elastic mechanical behaviour for the phases, Wen et al [27] showed that the plate orientation in the favourable direction is maximal at the beginning of the transformation (fig.7). The orientation becomes more random as the martensite content increases (the mean transformation strain does not vary anymore when martensite content increases). When applied stress increases, the number of plates with favourable orientation increases and the content of martensite at which the distribution becomes more random is increases too.

Marketz et al [9] used also a 2D FEM. In their model the mesh was caracterizing different grains with different orientations. In each grain, the plates were able to form according to 24 different orientations. The mechanical behaviour of the phases was elasto plastic. The transformation kinetics was considered as an input data i.e. the local stress did not trigger the transformation kinetics, it only gives an additional driving energy, and so allows some more favourable plates orientation to be formed if they reach a critical energy. All orientations which have a driving force larger than the critical energy are formed. The transformation plasticity deformation as defined previously calculated by these authors for transformation during cooling under different constant stresses are shown figure 8a. The calculated results are very near the experimental ones. The relative contribution of the plates orientation is shown figure $8 \mathrm{~b}$. This figure reveals that for the lower applied stress; the transformation plasticity deformation is essentially (80\%) due to the orientation of the plates. When the stress is increased, the relative contribution of the plate orientation is reduced to 40$60 \%$ for the larger stress. It is also clear that the plate orientation is maximal at the beginning of the transformation and the contribution is reduced as transformation progresses. For the larger stress the behaviour seems slightly different.

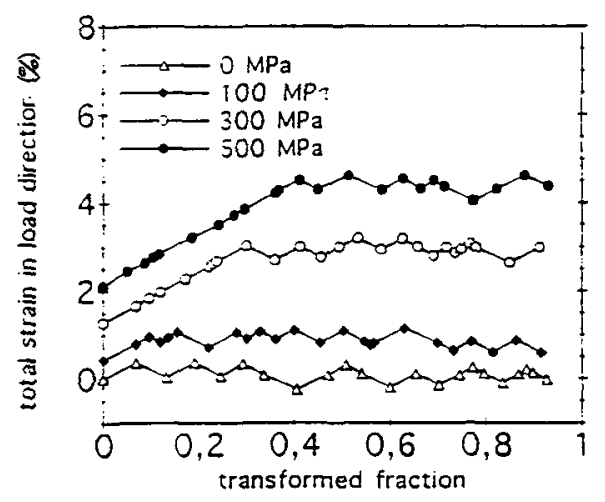

Figure 7 : Calculated macroscopic strain versus fraction martensite transformed for different applied stresses from [27]
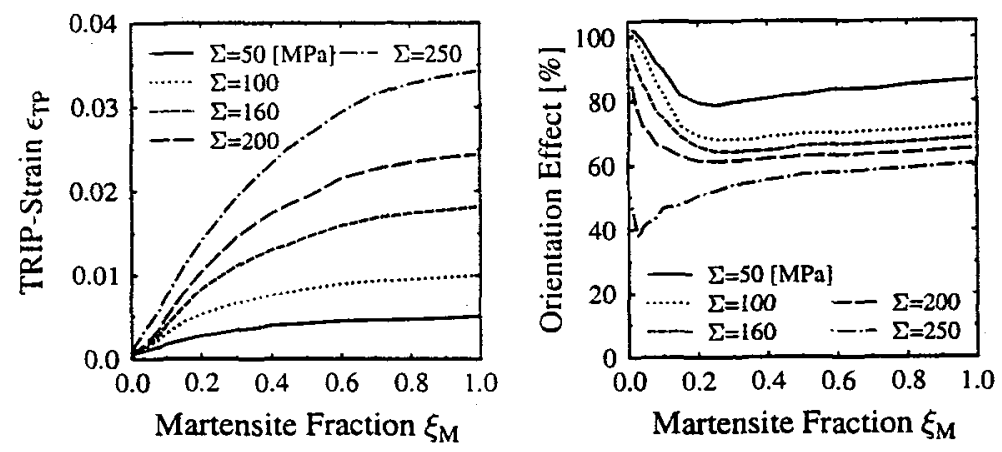

Figure 8 : a) Transformation plasticity deformation versus martensite content for different external applied stresses. b) Relative contribution of the plates orientation to the overall transformation plasticity deformation. From [9].

At last Simonsson [10] developed a 3D model with different grains considering 24 plates orientation per grain and an elasto plastic behaviour of the phases. The transformation kinetics is calculated. The plate orientation is determined by maximizing the work associated to the transformating plate and self accommodating groups of plates are formed. The transformation plasticity deformation evolution versus 
stress is nearly well described, however the contribution of plates orientation is too low. Again, for low applied stresses the transformation plasticity is only related to the plate orientation mechanism.

For all these models different hypothesis were made and all the complexity of the martensitic transformation is not considered. However, they confirm the schemes described previously.

\section{TRANSFORMATION PLASTICITY DURING PLASTIC DEFORMATION}

The transformation plasticity deformation was experimentaly determined during tensile testing. It corresponds to the deformation occuring simultaneously to the transformation, that is the yielding occuring in the absence of transformation was not taken into account $[13,25,26]$.

Figure 9 shows the variations of the transformation plasticity deformation and the corresponding applied stress versus the martensite content at different test temperatures, for the Fe-20Ni-0.5C alloy. The loading rate was of $1.5 \mathrm{MPa} / \mathrm{s}$. Results indicate that i) for a given martensite content, the transformation plasticity deformation increases with the test temperature ii) for a given martensite content, the transformation plasticity depends on the deformation range (elastic or plastic deformation range of austenite, $\sigma_{y} \approx 200$ $\mathrm{MPa}$ ) ii) a more important transformation plasticity deformation is obtained when the transformation occurs at a higher value of $\sigma / X$ (i.e. at a same martensite content $X$ the transformation plasticity is larger if the stress is larger, or at a same stress, the transformation plasticity is larger if the amount of martensite formed before is lower).
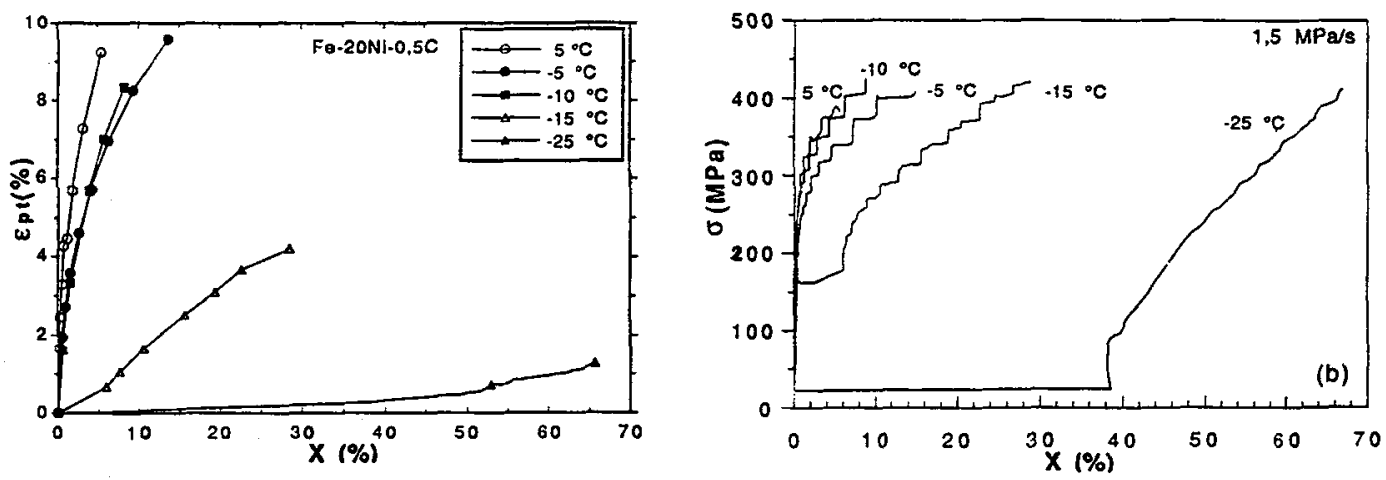

Figure 9 : Transformation plasticity deformation and stress variations versus martensite content during different tensile tests.

A larger transformation plasticity deformation as the one obtained during transformation under constant stress is observed if the transformation occurs in the plastic deformation domain of the austenite The comparison between the two types of thermomechanical tests shows that some additional phenomena occurs in the plastic deformation range. In figure 10 are plotted the variations of $\varepsilon_{\mathrm{pt}}$ versus $\mathrm{X}$ for two types of tests. Transformation plasticity deformation is quite larger during the tensile test. Moreover, the large deformations are only observed in the plastic deformation range (fig.9). In the elastic range, the value obtained is about 0.08 . The results obtained for the $\mathrm{Fe}-25 \mathrm{Ni}-0.66 \mathrm{C}$ alloy during tensile tests give comparable results at different test temperatures in the range $\mathrm{Ms}-\mathrm{Ms}+30^{\circ} \mathrm{C}$. The transformation plasticity deformation normalized by the transformation content $\left(\Delta \varepsilon_{\mathrm{p}} / \Delta \mathrm{X}\right)$ varies in the range [0.2 - 0.8$]$ when the transformation occurs in the plastic deformation range. Numerical simulations lead to a value of $\Delta \varepsilon_{\mathrm{p}} / \Delta \mathrm{X}$ equal to $=0.2$ with a complete preferential orientation and the transformation strains being accommodated by plastic deformation in the austenite [8].

To understand the origins of these large deformations, microstructural observations of martensite formed during plastic deformation were performed for different $\mathrm{Fe}-\mathrm{Ni}-\mathrm{C}$ alloys $[30,31,33]$. From these studies it was shown that the martenste morphology changes when it is formed during deformation. The habit plane of the plates are modified either from (225)f to (111)f [30] or from (259)f to (111)f [31] when the applied stress or the test temperature increase. The structure of the (111)f martensite consists of a high dislocation 
density without transformation twins.The length and width of the plates are decreased. This result is similar to the decrease in width observed for the Fe-20Ni-0.5C alloy formed during cooling under stress (fig 4).

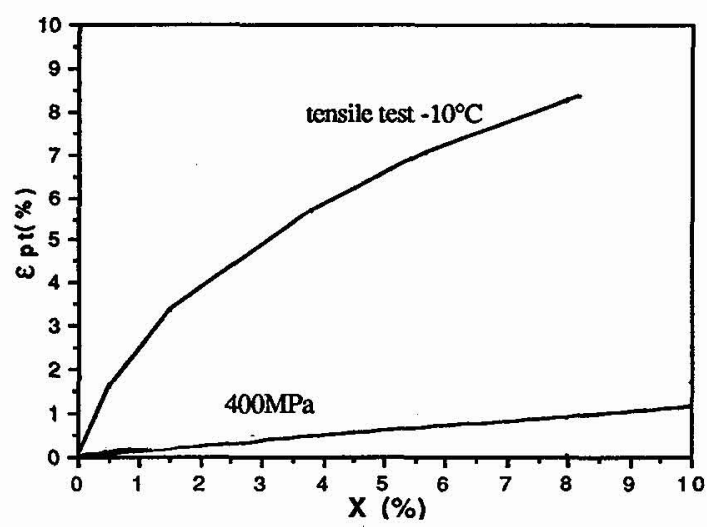

Figure 10 : Comparison of the two tests. Variations of $\varepsilon_{\mathrm{pt}}$ versus $\mathrm{X}$ during a tensile test and a cooling test under constant stress.

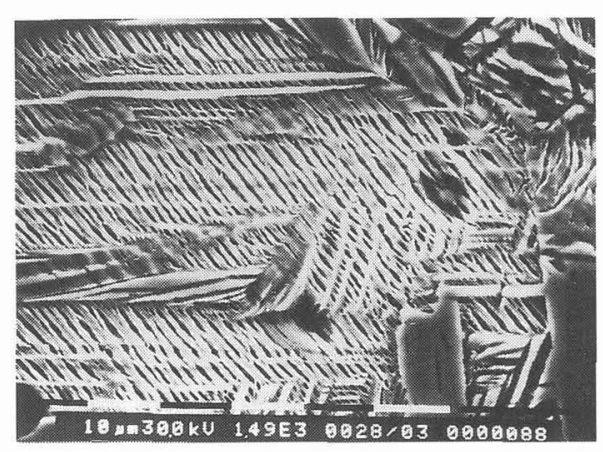

Figure 11 : Microstructure of martensite formed in an Fe-25Ni-0.66C alloy formed during a tensile test at $-120^{\circ} \mathrm{C}\left(\mathrm{Ms}=-153^{\circ} \mathrm{C}\right)$. SEM observation.

The decrease in size can be related to the limited growth due to a higher interaction of the interface with dislocations [32], these dislocations being mostly due to the plastic accommodation in the parent phase. The plate morphology modifications (habit plane, internal structure) are related to modifications in the Bain strain accommodation mechanism [30,31].

In analogy to the transformation plasticity deformation proposed by Roytburd [16] where the behaviour of the phases are elastic and the interfaces stay coherent, domains for a given Bain strain with preferred orientation will be formed. Such preferred orientation in different plates for the $\mathrm{Fe}-25 \mathrm{Ni}-0.66 \mathrm{C}$ alloy formed during a tensile test is shown figure 11 and further detailed in [33]. In this case, twins are still observed under stress.

When transformation occurs in the plastic deformation range of the austenite, oriented domains are formed. The internal stresses due to transformation will be more and more relaxed by plastic deformation in the parent phase. A limiting case can be a complete relaxation by plastic deformation in the parent phase. As a consequence, the transformation plasticity deformation increases. Again both "mechanisms" of transformation plasticity are acting : orientation of domains (the strain tensor of the domains being the Bain strain tensor) and plastic accommodation of the Bain strain as we schematized it fig. 6 . Also larger values of transformation plasticity, nearer to the one observed experimentally could then be calculated.

At last it must be noted that the large transformation plasticity deformation is only observed for transformation during plastic deformation (not during cooling). This was attributed to some moving dislocations existing for the tensile tests. A further analysis of the transformation during plastic deformation would be necessary to better understand these observations.

\section{CONCLUSIONS}

Transformation plasticity mechanisms were reviewed for the martensitic transformation in ferrous alloys. Experimental measurements, microstructural observations and numerical simulations lead to the following conclusions :

- for low applied stresses the only mechanism acting is the change in the plate orientation distribution.

- when the stress is increased, the possible plastic accommodation of the shear strain intervenes which allows a larger contribution of plate with favourable orientation. For a constant stress, the contribution of the plate orientation lowers as the amount of martensite increases.

- the plastic accommodation of the volumic and the shear strains intervenes at stresses equal to roughly $1 / 3$ of the yield stress of the austenite.

- the large transformation plasticity deformation in the plastic deformation range observed during tensile test is attributed to a change in the transformation mechanisms namely a modification of the Bain strain 
accommodation. Moreover domains (or twins) of preferred orientation in regard to the applied stress are formed

\section{Acknowledgments}

The authors are grateful to CNRS and ACADEMIA SINICA and NSFC for the financial support of the cooperation.

\section{References}

[1] Scheil E., Z. Anorg. Allg. Chem. 207 (1932) 21.

[2] Tamura I., Met. Sci.16 (1982) 245.

[3] Wayman C.M., International Conference on the Strength of Metals and Alloys ICSMA7, Montreal August 12-16 Aout 1985 , H.J. Mc Queen, J.P. Bailon, J.I. Dickson, J.J. Jonas, M.C. Akben Eds (Pergamon Press, 1985) pp 1779 - 1805.

[4] Olson G.B., Deformation Processing and Structure Ed. G Krauss (ASM 1984) pp391-424.

[5] Stringfellow R.G., Parks D.M. and Olson G.B., Acta metall. mater. 40 (1992) pp 1703-1716.

[6] Diani J.M. Berveiller M.Sabar H., Int Journ. of Engineering Science (in the press).

[7] Denis S., Sjöström S. and Simon A. Metall. Trans. 18A (1987) 1203-1212.

[8] Ganghoffer J.F., Simonsson K., Denis S., Gautier E., Sjöström S., and Simon A., ICOMAT 92 Monterey 20-24 July 1992, C.M. Wayman and J. Perkins Edts (Monterey Institute for Advanced Studies 1993) pp 341-346.

[9] Marketz F. and Fischer F.D., PTM 94' Solid Solid Phase Transformation Nemacolin Woodlands Farmington, Pennsylvania July 17-22,1994, Edts Johnson W.C., Howe J.M., Laughlin D.E., Soffa W.A., (TMS 1994) pp 785-790

[10] Simonsson K. Dissertation Thesis Linköping University 1995.

[11] Magee C.L. Ph D Thesis, Carnegie Mellon University 1966.

[12] Patoor E., Eberhardt A., Berveiller M., Acta Metall.35 (1987) 2779.

[13] Gautier E., Zhang X.M. and Simon A.; Proc. ICRS2, Ed. G. Beck, S. Denis, A. Simon (Elsevier Applied Science, 1988) pp 777- 782.

[14] Kosenko N.S., Roytburd A.L. and Khandros L.G. Phys. Met. Metall. 44 (1979) 48-56.

[15] Pankova M. and Roytburd A.L., Phys. Met. Metall. 58 (1984) 81-90.

[16] Roytburd A.L., Mecamat 95 La Bresse 16-19 Mai 1995, Les Editions de Physique to be published.

[17]. de Jong M, Rathenau G.W., Acta Metall. 7 (1959) p 246,

[18] de Jong M., Rathenau G.W., Acta Metall. 9 (1961) p 714.

[19] Greenwood G.W., Johnson R.H.; Proc. R. Soc. 283A, 1965, 403.

[20] Gautier E., Simon A. and Beck G.; Acta Metall. 35 (1987) 1367.

[21] Leblond J.B., Devaux J. and Devaux J.C., Int. Jour. of Plasticity 5 (1989) 551-572.

[22] Ganghoffer J.F., Denis S. Gautier E. Simon A. and Sjöström S., Eur. J. Mech, A/Solids, 12 (1993) pp 21-32.

[23] Roytburd A.L. and Kurdjumov G.V. Materials Science and Engineering 39 (1979) 141-167.

[24] Abrassart F.; Thèse de Docteur d'Etat, Université de Nancy,France, 1972.

[25] Gautier, E. Simon A.and Beck G.; Proc. 7th Int. Conf. on Strengh of Metals and Alloys, Montreal, Canada, Pergamon Press, 1985, 569 and Proc. Int. Conf. Solid-Solid Phase Transformations Cambridge 6-10 July, Edt G.W. Lorimer (The Institute of Metals, 1987) pp 285-287

[26] Zhang J.S. Thèse de Doctorat de l'INPL Nancy France 1993.

and Zhang J.S., Gautier E. and Simon A.,ICOMAT 92 Monterey 20-24 July 1992, C.M. Wayman and J. Perkins Edts (Monterey Institute for Advanced Studies 1993) pp 503-508.

[27] Roytburd A.L. Phys. Stat. sol. (a) 40 (1977) pp 333-342 and private communication.

[27] Wen Y.H., Denis S. and Gautier E., Mecamat 95 La Bresse 16-19 Mai 1995, Les Editions de Physique to be published.

[28] Wen Y.H. Denis S. and Gautier E., Journal de Physique IV Colloque C2, supplément au Journal de Physique III 5 (1995) pp 531-536.

[30] Zhang X.M., Gautier E. and Simon A.; Acta metall. 37 (1989) pp 487-497.

[31] Zhang X.M., Li D.F., Xing Z.S., Gautier E., Zhang J.S. and Simon A. ; Acta metall. mater. 41 (1993) $1683-1689$.

[32] Grujicic M., Ling H.C., Haezebrouck D.M., Owen W.S. in Martensite Eds Olson G.B. and Owen W.S. (ASM International 1992) pp175-196.

[33] Zhang X.M., Hu T.R., Meng X.M., Li Y.Y., Gautier E. and Zhang J.S. this conference. 